\title{
SMALl AIRWAY DISEASE IN COPD ASSOCIATED TO BIOMASS EXPOSURE
}

\author{
Alejandra Ramírez-Venegas ${ }^{1 *}$, Carlos Arturo Torres-Duque ${ }^{2}$, Nicolás Eduardo Guzmán-Bouilloud ${ }^{1}$, \\ MaUricio González-García ${ }^{3}$ and Raúl H. Sansores ${ }^{4}$
}

\begin{abstract}
1Department of Research in Tobacco and COPD, Instituto Nacional de Enfermedades Respiratorias Ismael Cosío Villegas, Mexico City, Mexico; ${ }^{2}$ Research Department, Fundación Neumológica Colombiana, La Sabana University, Bogota, Colombia; ${ }^{3}$ Research Department, La Sabana University, Bogota, Colombia; ${ }^{4}$ Department of Respiratory Medicine, Fundación Médica Sur, Mexico City, Mexico
\end{abstract}

\begin{abstract}
Chronic obstructive pulmonary disease (COPD) is a complex and heterogeneous entity that may result from different causative agents and risk factors and may follow diverse clinical courses, including COPD secondary to biomass smoke exposure. At present, this phenotype is becoming more important for two reasons: first, because at least almost half of the world's population is exposed to biomass smoke, and second, because the possibility of it being diagnosed is increasing. Biomass smoke exposure COPD affects primarily women and is related with insults to the airways occurred during early life. Although constituents of biomass smoke and tobacco smoke are similar, the physiopathological changes they induce differ depending not only on the chemical composition (related with the type of fuel used) but also on the particle size and the inhalation pattern. Evidence has shown that biomass smoke exposure affects the airway, predominantly the small airways causing anthracofibrosis and peribronchiolar fibrosis changes that will clinically translate into chronic bronchitis symptoms, with a high impact on the quality of life. In this review, we focus especially on the main epidemiological and clinical differences between COPD secondary to biomass exposure and COPD caused by tobacco exposure. (REV INVEST CLIN. 2019;71:70-8)
\end{abstract}

Key words: Chronic obstructive pulmonary disease. Biomass. Small airway disease phenotype.

\section{INTRODUCTION}

Chronic obstructive pulmonary disease (COPD) is a heterogeneous disease in terms of clinical presentation, lung function, comorbidities, exacerbations, and quality of life, among other features ${ }^{1}$. Conventionally, two major phenotypes of COPD were considered, i.e., emphysema and bronchiolitis also referred to as "small airways disease." However, many of the old concepts have changed. Today, it is generally accepted that COPD is not one single entity, but rather a complex and heterogeneous group of disorders, which may result from different causative agents and risk factors and have diverse clinical courses $^{2-5}$; such is the case of COPD secondary to biomass smoke exposure (BECOPD). In particular, this phenotype of COPD has relevance since almost half of the global population is exposed to biomass smoke, especially in rural areas

\section{Corresponding author:}

*Alejandra Ramírez-Venegas

Department of Research in Tobacco and COPD

Instituto Nacional de Enfermedades Respiratorias

Ismael Cosío Villegas (INER)

Calzada de Tlalpan, 4502

Col. Sección XVI, Del. Tlalpan

C.P. 14080, Mexico City, Mexico

E-mail: aleravas@hotmail.com 
from developing countries ${ }^{6}$. Research data from BECOPD have developed slowly in comparison with data from tobacco-exposed COPD (TE-COPD); nevertheless, there is sufficient information to describe the clinical, functional, histological, and imaging features of the BE-COPD phenotype ${ }^{7,8}$.

In this review, we analyze the epidemiology of the disease and the damage caused mainly to the small airway. We also describe differences between the BECOPD and the TE-COPD phenotypes.

\section{DIFFERENCES IN THE EPIDEMIOLOGY OF BIOMASS AND TOBACCO EXPOSURES}

\section{The origins of biomass exposure}

Biomass is defined as an organic matter that can be used as a fuel including wood, animal waste (manure), crop, and forestry residues, among others ${ }^{9}$. Biomass, either wood or its derivatives, shares many properties and substances with tobacco. However, regarding their epidemiology, the main difference between biomass exposure and tobacco exposure and, therefore, with COPD expression, is related with the socioeconomic context in which these exposures occur. The tobacco epidemic developed as a result of innovations in the tobacco industry between 1913 and 1920; later, during the $60 \mathrm{~s}$, the cigarette industry experienced almost uninterrupted growth in the United States and over the world ${ }^{10}$, killing thousands of millions of people. In contrast, biomass exposure has existed since humans began using organic fuel materials for cooking and heating, affecting billions of women and children ${ }^{11}$; unfortunately, for centuries, there has been no awareness of the impact on the health of exposed individuals ${ }^{12}$. These individuals, especially women, have gone unnoticed by governments and also by the research community.

While tobacco smoking was promoted by the tobacco industry for recreational purposes, developing a need to smoke tobacco ${ }^{13}$, the use of biomass has been a necessity for women in rural areas for subsistence, cooking, and household heating since poverty has prevented them from having access to electricity and safer fuels ${ }^{14}$.
The World Health Organization has estimated that there are around 1100 billion persons exposed to tobacco globally, while for biomass exposure, it is half of the world's population, or about 3 billion people, who rely on solid fuels for cooking and heating. This proportion is higher in developing countries, especially in rural areas ${ }^{14}$.

\section{Biomass as an indoor air contaminant: a cause of COPD in women}

As women tend to stay indoors most of the time, exposure to contaminants inside the homes dominates the list of exposure to various pollutants worldwide, especially in developing countries. In most cultures, women have a leading role in domestic cooking, while men are at work or away from home. Globally, almost $50 \%$ of deaths from COPD in developing countries could be attributed to biomass exposure, and approximately $75 \%$ of these are in women ${ }^{16}$.

COPD is the disease with the highest evidence, reported in different studies that women exposed to indoor smoke are 3 times more likely to suffer from COPD in the form of chronic bronchitis than women who cook with electricity, gas, or other cleaner fuels ${ }^{17}$. For example, in Colombia, it was found that the use of a biomass stove for 10 or more years was associated with a greater risk of COPD (GOLD Stage 1 or greater; OR, $1.5 ; 95 \% \mathrm{Cl} 1.22-1.86)^{18}$. At present, COPD associated with indoor air pollution from biofuels is considered a public health issue with a double significance: it is a gender-specific disease, occurring almost exclusively in women, and, on the other hand, an increasing number of women are being affected worldwide ${ }^{17}$.

\section{Early COPD: factors that contribute to airway damage since childhood}

It is very common for women to have several periods of exposure to intense cooking smoke each day, occurring indoors in unvented open fires that operate at low temperatures. This produces a great variety of air contaminants. The levels of pollutants inside homes burning biomass in unvented open fires are incredibly high, in the milligram per cubic meter range ${ }^{19-22}$. Women are exposed to biomass smoke at all stages of life, during pregnancy and childhood and especially during adolescence when 
they begin to cook. Therefore, women and girls receive the largest cumulative exposures throughout their lives, since they spend an average of 4-8 $\mathrm{h}$ daily in the kitchen, usually in an enclosed space with poor ventilation. Consequently, during their lifetime, women are exposed to biomass smoke for 30-40 years, the equivalent of $60,000 \mathrm{~h}$ of exposure, or inhaling a total volume of 25 million $L$ of polluted indoor air ${ }^{23}$.

Celli et al. recently wrote that the beginning of the disease is not a firmly defined concept ${ }^{3}$. The natural history of a disease is sometimes said to start at the moment of exposure to a causal agent in an individual susceptible to it ${ }^{3,24}$. The age of onset of biomass and tobacco exposures is different. Biomass exposure begins much earlier in life (in utero and from the neonatal period) than does active smoking (usually in the teenage years), thereby increasing the risk for COPD in relative terms ${ }^{25,26}$. In addition, young children and infants, who are typically carried on the back or placed near their mother to sleep, are also exposed to biomass smoke ${ }^{14}$. There is a particular concern when young children are exposed to smoke because data suggest that smoke exposure during the window of developmental susceptibility in early life is particularly detrimental ${ }^{26}$. Chronic insult beginning in childhood may act as an early stimulus that affects airway structure and function ${ }^{27}$. The early years are crucial because diseases associated to exposure can affect lung function throughout life. Children exposed to biomass smoke have a larger number of acute respiratory infections, including pneumonia, and asthma compared to unexposed children ${ }^{28,29}$. The consequence is a lower growth in lung function, leading to COPD $^{25}$.

Conversely, exposure to tobacco usually begins in adolescence, is intermittent, for very short periods, and most of the time occurs in open spaces. Assuming that smoking exposure was the "only" causal agent of COPD, the absence of an early exposure in the first year of life would prevent the detrimental factors from damaging the airway in these children, i.e., lung growth in the first year of life is not affected in those future smokers ${ }^{30}$.

In other words, TE-COPD begins when a young individual starts to smoke, most often in adolescence, while BE-COPD starts in early childhood ${ }^{31}$.

\section{Variations in biomass and tobacco smokes inhalation lead to differences in damage location}

The differences between biomass and tobacco COPD phenotypes begin with the smoke source. Although biomass smoke has many of the same constituents as tobacco smoke, the exact composition differs depending on the source of the fuel, combustion efficiency, and relative humidity. Although the particle size may be similar in both tobacco and biomass smoke ${ }^{21,32}$, differences in chemical composition could lead to variation in the pathophysiological processes. Another difference between BE-COPD and TE-COPD is the pattern of smoke inhalation. Individuals inhaling biomass smoke use a consistent tidal breathing pattern. This type of inhalation pattern probably prevents the damage from spreading beyond the small airway, leading to an airwaypredominant COPD phenotype. The greatest damage from inhaling biomass components is located in the small airway that functions as the final part of the funnel, where an important inflammatory reaction takes place followed by remodeling of the small airway ${ }^{8}$.

Conversely, cigarette smokers usually smoke in a twophase pattern: first, the smoke is drawn into the mouth without direct inhalation into the lungs, then there is a pause, and finally, the smoke is inhaled into the lungs with an additional volume of air ${ }^{32}$. The average inhalation volumes have been measured at nearly $25 \%$ of vital capacity; this corresponds to close to twice the average tidal volume ${ }^{32}$. The larger inhalation volume in cigarette smokers compared to those exposed to biomass smoke may allow the smoke to reach more deeply into the lungs and may increase the deposition of tobacco smoke in the lung parenchyma, leading to an emphysema-predominant COPD phenotype.

This contrasting epidemiological context between women using biomass fuel and smokers allows for a better understanding of the differences in the clinical picture and the functional, histologic, and tomographic findings of COPD between these two phenotypes ${ }^{33}$.

\section{AIRWAY DAMAGE IN COPD FROM EXPOSURE TO BIOMASS SMOKE}

A growing body of evidence supports that COPD caused by chronic indoor exposure to biomass smoke, 
in contrast to COPD due to cigarette smoke, is predominantly a disease of the airways with mild or minimum emphysema ${ }^{6-8,34-38}$. Although recent studies have focused on the small airways' damage in $\mathrm{BE}-\mathrm{COPD}^{8,38}$, bronchial anthracofibrosis affecting also the central airways seems a trait more frequent and severe in BE-COPD than in TE-COPD, which could cause bronchial stenosis ${ }^{8,39-41}$. In the following paragraphs, we present some of the evidence and characteristics of the airways' damage in BE-COPD.

\section{Histological and tomographic findings}

Pathological studies of samples obtained from bronchial and lung biopsies and from autopsies in persons chronically exposed to biomass smoke, with or without a diagnosis of COPD, revealed an important thickening of the bronchial wall, mainly of its basal membrane, squamous-cell metaplasia, goblet cell hyperplasia, peribronchiolar fibrosis, and bronchiectasis with a remarkable anthracotic pigment deposition in the bronchi and pulmonary interstitium $7,8,33,42-44$. Among these findings, in the study by Rivera et al., ${ }^{33}$ the autopsies of 10 women with BE-COPD and 10 women with TE-COPD showed greater remodeling and more fibrosis in the small airway in BE-COPD compared to TE-COPD. This is a clear evidence that the damage to the small airway is the main pathological feature in BE-COPD. Figure 1 shows an example of the severity of damage to the small airway in BE-COPD.

Importantly, these pathological changes are well correlated with the radiographic findings, whether in the chest X-ray or the computed tomography $36,37,42,45,46$. High-resolution computed tomography (HRCT) scans show peribronchial thickening, bronchial dilation, laminar subsegmental atelectasis, mosaic perfusion pattern, parenchymal bands, and no significant emphysema ${ }^{36-38,46}$. Using parametric response mapping, an imaging tool that allows the quantification of small airway disease and emphysema in COPD, Fernandes et al. confirmed the absence of important emphysema in patients with BE-COPD but, interestingly, suggested that these patients had a distinct pattern of small airway disease ${ }^{38}$.

\section{Clinical findings}

The vast majority of persons with BE-COPD are wom$\mathrm{en}^{47}$, who strikingly and consistently have a body
Figure 1. Membranous bronchioles with structural remodeling from mild (1) to severe (4) in chronic obstructive pulmonary disease (COPD) secondary to biomass. Courtesy of Dr. Rivera. Material obtained from the autopsy of a woman with BE-COPD.
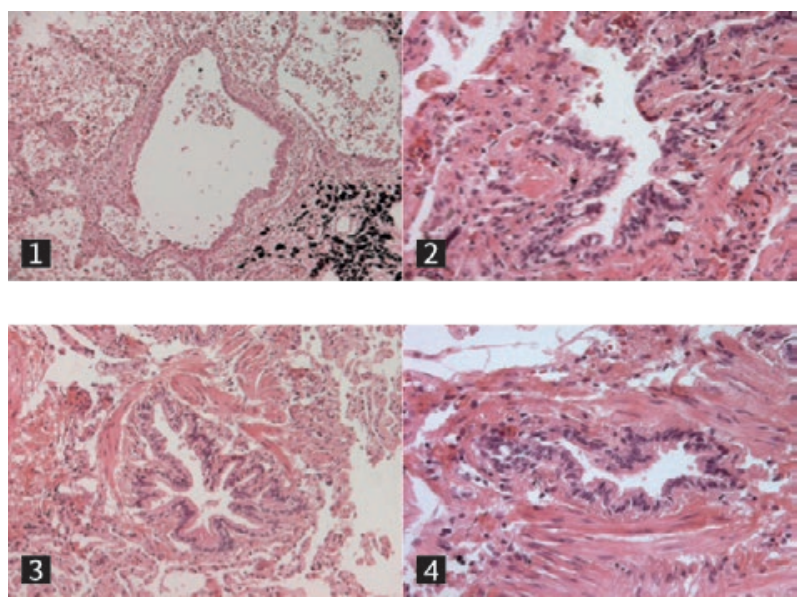

mass index (BMI) higher than that of people with TE-COPD $6,8,34,48$. Individuals exposed to biomass smoke have a high risk of chronic bronchitis (cough and phlegm for $\geq 3$ months per year for at least 2 consecutive years $)^{49,50}$ and patients with BE-COPD frequently have respiratory symptoms: cough, expectoration, and dyspnea ${ }^{36,42,45,51}$. Some studies show that these symptoms are more frequent or have more impact in BE-COPD than in TE-COPD ${ }^{36,45,52,53}$, but other studies do not $48,51,54,55$. With regard to the physical examination, rhonchus and wheezing are relatively frequent in $\mathrm{BE}-\mathrm{COPD}^{45}$. The high frequency of cough, expectoration, rhonchus, and wheezing is clearly indicating the predominant damage to the airways in BE-COPD.

\section{Quality of life}

It is well known that COPD negatively affects the quality of life. Some studies have shown that this negative impact is higher in BE-COPD. Camp et al., using the St. George's Respiratory Questionnaire, found worse symptoms and more compromised activity indexes in women with BE-COPD compared to those with TE-COPD ${ }^{36}$. Another study including 138 women with COPD showed that among women with the same degree of obstruction, those with BE-COPD had worse health status (poorer quality of life and worse dyspnea) than those with TE-COPD, with no differences in comorbidities ${ }^{52}$. 
Figure 2. A: $\mathrm{FEV}_{1}$ annual decline in biomass smoke exposure-chronic obstructive pulmonary disease (BE-COPD) compared to tobacco-exposed chronic obstructive pulmonary disease (TE-COPD) and healthy subjects. This figure shows an annual decline of almost twice the value in patients with TE-COPD compared to BE-COPD. The variability in the mean annual decline in TE-COPD was broader. B: $-41.7 \pm 26.2 \mathrm{~mL}$, while the variability in the BE-COPD was narrower. C: $-23.1 \pm 16.9 \mathrm{~mL}$.

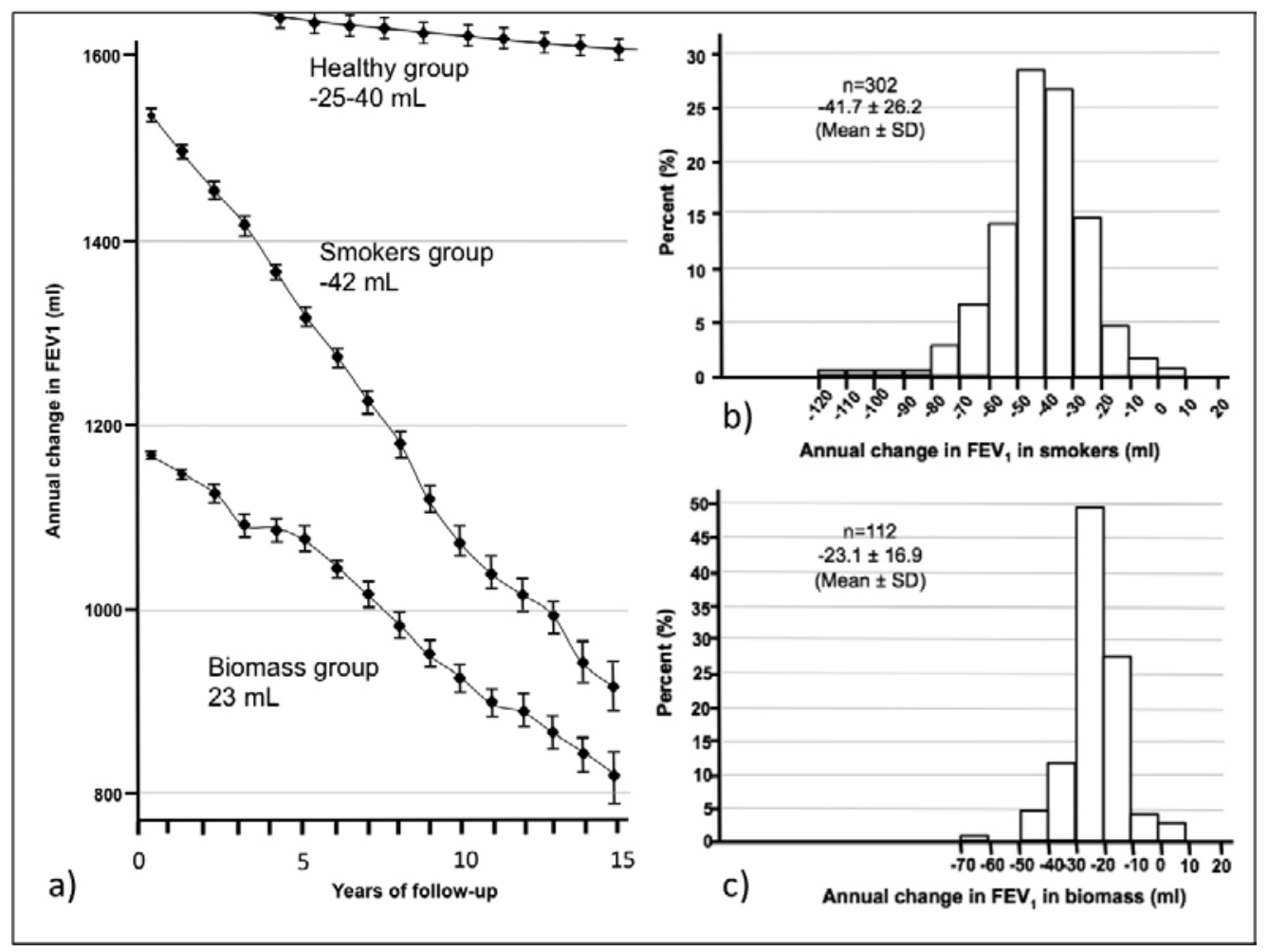

\section{Functional findings}

By definition, patients with BE-COPD have post-bronchodilator airflow obstruction: $\mathrm{FEV}_{1} / \mathrm{FVC}<0.7$ or $<$ lower limit of normal. Compared with TE-COPD, obstruction in BE-COPD is milder, both overall and after adjusting for age ${ }^{36,42,45,48,54,56-58}$. Regarding the annual decline in lung function, the time-course behavior of $\mathrm{FEV}_{1}$ in a Mexican cohort of patients with COPD associated with biomass or tobacco during a 15 -year follow-up period showed that the rate of FEV 1 decline was significantly slower in patients whose COPD was caused by biomass smoke than in those caused by tobacco exposure. The annual rate of decline was significantly higher in the TE-COPD group than in the BE-COPD group (42 mL vs. $23 \mathrm{~mL}$, respectively, $p<$ 0.001 ). The proportion of rapid decliners in patients with COPD caused by biomass fuel was very low (1\%) compared with the one seen in patients whose COPD was caused by tobacco exposure (11\%) (Fig. 2$)^{57}$.
With respect to gas exchange, some studies have shown that carbon dioxide arterial pressure $\left(\mathrm{PaCO}_{2}\right)$ is higher (lower ventilation) and oxygen arterial pressure $\left(\mathrm{PaO}_{2}\right)$ and oxygen arterial saturation $\left(\mathrm{SaO}_{2}\right)$ are lower in BE-COPD than in TE-COPD ${ }^{36,45,54,57}$. The lower oxygenation rates observed in BE-COPD may be explained in part by hypoventilation. It remains to be determined whether this behavior is related with a higher BMI in these patients, most of whom are women over 50 years of age. Recently, Olloquequi et al. found that patients with COPD exposed to both biomass and cigarette smoke exhibit significantly lower oxygen saturation than those exposed to only biomass or only cigarette smoke ${ }^{55}$.

Normal or mildly altered diffusing capacity $\left(\mathrm{DL}_{\mathrm{CO}}\right)$ and $\mathrm{DL}_{\mathrm{CO}}$ /alveolar volume (DLCO/AV) ratio are consistently observed in BE-COPD when they are compared to TE-COPD, in which these parameters are significantly reduced $37,45,55$. This finding correlates with the lower 
Figure 3. Bronchial hyperreactivity evaluated by $\mathrm{PC}_{20}$ by exposure (59). White circles: biomass smoke exposure-chronic obstructive pulmonary disease (BE-COPD); black circles: tobacco-exposed chronic obstructive pulmonary disease (TE-COPD). $\mathrm{PC}_{20}$ geometric mean: $\mathrm{BE}-\mathrm{COPD}$ versus $\mathrm{TE}-$ COPD: 0.39 (0.06-5.13) versus 1.24 (0.34-9.39), $p=0.028$. $\mathrm{PC}_{20}$ : methacholine concentration causing $\geq 20 \%$ reduction in $\mathrm{FEV}_{1}$.

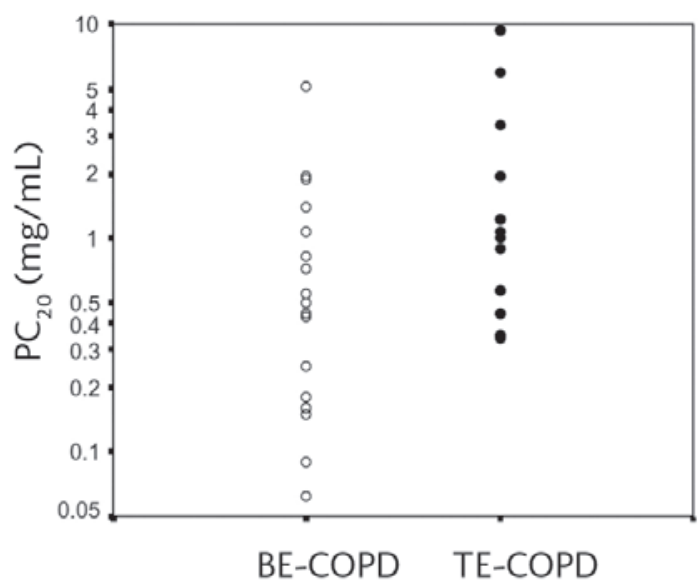

grade of emphysema found in HRCT in patients with $\mathrm{BE}-\mathrm{COPD}^{8,36-38,46}$ at all levels of COPD severity. This functional picture of decreased $\mathrm{DL}_{\mathrm{CO}}$ with normal DLCO/AV has been described in cases with significantly compromised small airways with little emphysema (pseudophysiological emphysema) ${ }^{59}$. Compromised diffusion correlates better with decreased $\mathrm{FEV}_{1}$ in women with TE-COPD than in those with BE-COPD, posing the greater contribution of emphysema to airflow obstruction in TE-COPD ${ }^{45}$.

Women with BE-COPD have greater bronchial hyperreactivity than women with TE-COPD (Fig. 3$)^{60}$. Further, research is needed to determine if this correlates with the higher frequency of the asthma-COPD overlap phenotype observed in $\mathrm{BE}-\mathrm{COPD}^{48}$. There is evidence also that small airway resistance measured by oscillometry is considerably more affected in BECOPD than in TE-COPD ${ }^{61}$.

\section{Exercise tolerance in BE-COPD}

The walked distance in the 6 min walking test in BECOPD does not seem significantly different compared to TE-COPD $36,52,54,55$, although Zhao et al. found a lower distance in $\mathrm{BE}-\mathrm{COPD}^{8}$. Camp et al. reported lower $\mathrm{SaO} 2$ measured by pulse oximetry at the end of the test in women with BE-COPD ${ }^{36}$.

\section{Clinical phenotypes in BE-COPD}

Golpe et al. ${ }^{48}$ evaluated that the frequency of clinical phenotypes defined by the Spanish COPD guidelines ${ }^{62}$ in patients with COPD caused by biomass or tobacco smoke. The asthma-COPD overlap phenotype was more common in BE-COPD, but the difference disappeared after adjusting for sex. Similar to the findings discussed in the previous sections, they found a greater frequency of emphysema phenotype in TE-COPD. No difference was found in the frequencies of chronic bronchitis or exacerbator phenotypes ${ }^{48}$.

\section{Pulmonary hypertension in BE-COPD}

A recent study found that pulmonary hypertension on echocardiography was more common in patients with

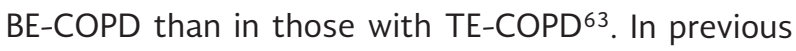
studies, González et al. based on radiographic evaluation, and Sandoval et al. showed a higher rate of pulmonary hypertension among individuals with COPD related to wood smoke exposure compared to those exposed to tobacco smoke ${ }^{45,64}$. The origin of pulmonary hypertension in BE-COPD patients does not appear to be related only to hypoxic pulmonary vasoconstriction but also to direct effects caused by the inhaled substances or indirect inflammatory-mediated effects ${ }^{65}$.

\section{Exacerbations and survival in BE-COPD}

Golpe et al. did not find differences in the annual rate of exacerbations comparing BE-COPD and TE-COPD ${ }^{48}$, but it should be noted that no prospective data are available on this aspect. After adjusting for age, sex, and disease severity, Ramírez-Venegas et al. and Golpe et al. did not find differences in survival between $\mathrm{BE}-\mathrm{COPD}$ and TE-COPD ${ }^{54,58}$.

Table 1 summarizes the most important epidemiological, clinical, functional, histological, and imaging differences between BE-COPD and TE-COPD.

\section{Summary}

No doubt BE-COPD is a disorder clearly associated with poverty and sociocultural issues. There is a direct impact on lung growth in these women that damage mainly the small airway. 
Table 1. COPD characteristics of subjects exposed to biomass in comparison with those of smokers.

Biomass

Epidemiological characteristics

Gender

Onset and duration of exposure

Education level and socioeconomic status

Location

Pattern of smoking

\section{Clinical characteristics}

Chronic bronchitis

Wheezing

Phlegm

Dyspnea

Quality of life

\section{Lung function}

$$
\begin{aligned}
& \text { Airflow obstruction } \\
& \mathrm{DL}_{\mathrm{CO}}
\end{aligned}
$$

Bronchial hyperresponsiveness

Annual lung function decline

\section{Small airway damage}

Small airway resistance

Computed tomography findings

Pathology pattern

Survival
Female

Lifelong exposure while cooking including prenatal and early childhood

Illiterate and low income

Rural areas from developing countries

Tidal breathing pattern. Smoke stays in the large and small airway

Aware of respiratory symptoms after 70 years of age

Very common

Very common

Very common

Common

More affected

Mild

Normal

Very common

Low or no decline

Extremely affected

Airway thickening, air trapping pattern Without emphysema

More anthracosis, small airway fibrosis, and pulmonary arteriole intimal thickening

Unadjusted lung function: better than tobacco

After adjusted by lung function: similar as tobacco
Tobacco

Predominantly male

Start at adolescence and lasting 3-5 decades of heavy smoking

Literate and medium to high income

Urban areas

Deep inhalation and smoke is inhaled into the distal lungs

Aware of respiratory symptoms after $50-60$ years of age

Common

Common

Common

Very common

Affected

Moderate-severe

Low

Less common

Rapid or lower decline

Affected

Emphysema predominates Less air trapping

More emphysema

Unadjusted lung function: worse than biomass

After adjusted by lung function: similar to biomass

$\mathrm{DL}_{\mathrm{co}}$ : carbon monoxide diffusing capacity; COPD: chronic obstructive pulmonary disease

However, in spite of these women being exposed to very high levels of pollutants while cooking, the consequent decline in $\mathrm{FEV}_{1}$ seems not as detrimental as that induced by tobacco. These findings could indicate that $\mathrm{BE}-\mathrm{COPD}$ may be classified as the benign version of COPD. Even so, despite having a higher baseline $\mathrm{FEV}_{1}$, the histological and tomographic findings in BECOPD show a more intense small airway damage in comparison with TE-COPD. Furthermore, in BE-COPD gas exchange abnormalities occur earlier, and patients have a worse quality of life than smokers.
Moreover, mortality is similar to the one observed in smokers.

\section{CONCLUSION}

The effect on the small airway of biomass is as harmful as that caused by smoke in the lung parenquima. Therefore, BE-COPD seems equally damaging than TE-COPD. 


\section{REFERENCES}

1. Agusti A, Calverley PM, Celli B, et al. Characterisation of COPD heterogeneity in the ECLIPSE cohort. Respir Res. 2010;11:122.

2. Han MK, Agustí A, Calverley PM, et al. Chronic obstructive pulmonary disease phenotypes. Am J Respir Crit Care Med. 2010; 182:598-604.

3. Celli BR, Agustí A. COPD: time to improve its taxonomy? ERJ Open Res. 2018;4:00132-2017.

4. Agustí A, Celli B. Natural history of COPD: gaps and opportunities. ERJ Open Res. 2017;3:00117-2017

5. Agustí A, Sobradillo P, Celli B. Addressing the complexity of chronic obstructive pulmonary disease. Am J Respir Crit Care Med. 2011;183:1129-37.

6. Pérez-Padilla R, Ramírez-Venegas A, Sansores-Martínez R. Clinical characteristics of patients with biomass smoke-associated COPD and chronic bronchitis, 2004-2014. Chronic Obstr Pulm Dis. 2014;1:23-32.

7. Assad N, Balmes J, Mehta S, Cheema U, Sood A. Chronic obstructive pulmonary disease secondary to household air pollution. Semin Respir Crit Care Med. 2015;36:408-21.

8. Zhao D, Zhou $Y$, Jiang $C$, et al. Small airway disease: a different phenotype of early stage COPD associated with biomass smoke exposure Respirology 2018;23:198-05.

9. Salvi SS, Barnes PJ. Chronic obstructive pulmonary disease in non-smokers. Lancet. 2009;374:733-43.

10. Slade J. The tobacco epidemic: lessons from history. J Psychoactive Drugs. 1989;21:281-91

11. Kodgule R, Salvi S. Exposure to biomass smoke as a cause for airway disease in women and children. Curr Opin Allergy Clin Immunol. 2012:12:82-90.

12. Biomass.net. Following the Energy Trail With Biomass History. Available from: http://www.biomass.net/Biomass-History.html. [Last accessed on 2018 Apr 10 th]

13. Hurt RD, Murphy JG, Dunn WF. Did we finally slay the evil dragon of cigarette smoking in the late $20^{\text {th }}$ century? Unfortunately, the answer is no-the dragon is still alive and well in the $21^{\text {st }}$ century and living in the third world. Shame on us! Chest. 2014; 146:1438-43.

14. Gordon SB, Bruce NG, Grigg J, et al. Respiratory risks from household air pollution in low and middle income countries. Lancet Respir Med. 2014;2:823-60.

15. Global Health Observatory. World Health Organization. Available from: http://www.who.int/gho/phe/en/. [Last accessed on 2018 Apr $10^{\text {th }}$ ].

16. Eisner MD, Anthonisen N, Coultas D, et al. An official American thoracic society public policy statement: novel risk factors and the global burden of chronic obstructive pulmonary disease. Am J Respir Crit Care Med. 2010;182:693-18.

17. Ramírez-Venegas A, Sansores RH, Velázquez-Uncal M, PérezBautista O. Nonsmokers and biomass exposure. ERS Monogr. 2015;69:35-46.

18. Caballero A, Torres-Duque CA, Jaramillo C, et al. Prevalence of COPD in five Colombian cities situated at low, medium, and high altitude (PREPOCOL study). Chest. 2008;133:343-9.

19. Balakrishnan K, Sambandam S, Ramaswamy P, Mehta S, Smith KR. Exposure assessment for respirable particulates associated with household fuel use in rural districts of Andhra Pradesh, India. J Expo Sci Environ Epidemiol. 2004; 14:S14-25

20. Balakrishnan K, Sankar S, Parikh J, et al. Daily average exposures to respirable particulate matter from combustion of biomass fuels in rural households of southern India. Environ Health Perspect. 2002;110:1069-75.

21. Naeher LP, Brauer M, Lipsett $M$, et al. Woodsmoke health effects: a review. Inhal Toxicol. 2007;19:67-6.

22. Brauer M, Hirtle RD, Hall AC, Yip TR. Monitoring personal fine particle exposure with a particle counter. J Expo Anal Environ Epidemiol. 1999:9:228-36.

23. Salvi S, Barnes PJ. Is exposure to biomass smoke the biggest risk factor for COPD globally? Chest. 2010;138:3-6.

24. Postma DS, Bush A, van den Berge M. Risk factors and early origins of chronic obstructive pulmonary disease. Lancet. 2015; 385:899-909

25. Heinzerling AP, Guarnieri MJ, Mann JK, et al. Lung function in woodsmoke-exposed Guatemalan children following a chimney stove intervention. Thorax. 2016;71:421-8

26. Hayatbakhsh MR, Sadasivam S, Mamun AA, et al. Maternal smoking during and after pregnancy and lung function in early adulthood: a prospective study. Thorax. 2009;64:810-4.
27. Kulkarni N, Pierse N, Rushton L, Grigg J. Carbon in airway macrophages and lung function in children. N Engl J Med. 2006; 355:21-30.

28. Mishra V, Retherford RD. Cooking smoke increases the risk of acute respiratory infection in children. Natl Fam Health Surv Bull. 1997;8:1-4

29. Po JYT, FitzGerald JM, Carlsten C. Respiratory disease associated with solid biomass fuel exposure in rural women and children: systematic review and meta-analysis. Thorax. 2011;66:232-9.

30. Martinez FD. Early-life origins of chronic obstructive pulmonary disease. N Engl J Med. 2016;375:871-8.

31. Stocks J, Hislop A, Sonnappa S. Early lung development: lifelong effect on respiratory health and disease. Lancet Respir Med. 2013;1:728-42.

32. Bernstein DM. A review of the influence of particle size, puff volume, and inhalation pattern on the deposition of cigarette smoke particles in the respiratory tract. Inhal Toxico. 2004; 16:675-89.

33. Rivera RM, Cosío MG, Ghezzo H, Salazar M, Pérez-Padilla R. Comparison of lung morphology in COPD secondary to cigarette and biomass smoke. Int J Tuberc Lung Dis. 2008;12:972-7.

34. Torres-Duque CA, García-Rodriguez MC, González-García M. Is chronic obstructive pulmonary disease caused by wood smoke a different phenotype or a different entity? Arch Bronconeumol. 2016:52:425-31.

35. Perret JL, Abramson MJ. Biomass smoke COPD: a phenotype or a different disease? Respirology. 2018;23:124-5

36. Camp PG, Ramírez-Venegas A, Sansores RH, et al. COPD phenotypes in biomass smoke-versus tobacco smoke-exposed Mexican women. Eur Respir J. 2014;43:725-34.

37. González-García M, Maldonado Gómez D, Torres-Duque CA, et al. Tomographic and functional findings in severe COPD: comparison between the wood smoke-related and smoking-related disease. J Bras Pneumol. 2013;39:147-54.

38. Fernandes L, Gulati N, Fernandes $Y$, et al. Small airway imaging phenotypes in biomass- and tobacco smoke-exposed patients with COPD. ERJ Open Res 2017; 3: 00124-2016.

39. Kim YJ, Jung CY, Shin HW, Lee BK. Biomass smoke induced bronchial anthracofibrosis: presenting features and clinical course. Respir Med. 2009;103:757-65.

40. Gupta A, Shah A. Bronchial anthracofibrosis: an emerging pulmonary disease due to biomass fuel exposure. Int J Tuberc Lung Dis. 2011;15:602-12

41. Kim H, Cha SI, Shin KM, et al. Clinical relevance of bronchial anthracofibrosis in patients with chronic obstructive pulmonary disease exacerbation. Tuberc Respir Dis. 2014:77:124-31.

42. Morán-Mendoza O, Pérez-Padilla JR, Salazar-Flores M, VázquezAlfaro F. Wood smoke-associated lung disease: a clinical, functional, radiological and pathological description. Int J Tuberc Lung Dis. 2008;12:1092-8.

43. Palacios DM, Méndez O. Neumopatía por humo de leña. Un estudio en autopsias. Biomédica. 1998;18:153.

44. Restrepo J, Reyes $P$, De Ochoa P, Patiño E. Neumoconiosis por inhalación del humo de leña. Acta Med Colomb. 1983;8:191-4.

45. González M, Páez S, Jaramillo C, Barrero M, Maldonado D. Enfermedad pulmonar obstructiva crónica (EPOC) por humo de leña en mujeres: comparación con la EPOC por tabaquismo. Acta Med Colomb. 2004;29:17-25.

46. Moreira MA, Barbosa MA, Queiroz MC, et al. Pulmonary changes on HRCT scans in nonsmoking females with COPD due to wood smoke exposure. J Bras Pneumol. 2013;39:155-63.

47. Sana A, Somda SM, Meda N, Bouland C. Chronic obstructive pulmonary disease associated with biomass fuel use in women: a systematic review and meta-analysis. BMJ Open Respir Res. 2018;5:e000246.

48. Golpe R, Sanjuán López P, Cano Jiménez E, Castro Añón O, Pérez de Llano LA. Distribución de fenotipos clínicos en pacientes con enfermedad pulmonar obstructiva crónica por humo de biomasa y por tabaco. Arch Bronconeumol. 2014;50:318-24.

49. González-Garcia M, Caballero A Jaramillo C, Torres-Duque CA Chronic bronchitis: high prevalence in never smokers and underdiagnosis-a population-based study in Colombia. Chron Respir Dis. 2018,1:1-8

50. Kurmi OP, Semple S, Simkhada P, Smith WC, Ayres JG. COPD and chronic bronchitis risk of indoor air pollution from solid fuel: a systematic review and meta-analysis. Thorax. 2010;65:221-8.

51. Moreira MA, Moraes MR, Silva DG, et al. Comparative study of respiratory symptoms and lung function alterations in patients with chronic obstructive pulmonary disease related to the exposure to wood and tobacco smoke. J Bras Pneumol. 2008. 34:667-74. 
52. González-García M, Gómez V, Perlaza I, Casas A. Diferencias en el impacto sobre el estado de salud entre la EPOC por cigarrillo y por humo de leña. Arch Bronconeumol. 2014;50:59.

53. Ramírez-Venegas A, Velázquez-Uncal M, Pérez-Hernández R, et al. Prevalence of COPD and respiratory symptoms associated with biomass smoke exposure in a suburban area. Int J Chron Obs Pulmon Dis. 2018;13:1727-34.

54. Ramírez-Venegas A, Sansores RH, Pérez-Padilla R, et al. Survival of patients with chronic obstructive pulmonary disease due to biomass smoke and tobacco. Am J Respir Crit Care Med. 2006;173:393-7.

55. Olloquequi J, Jaime S, Parra V, et al. Comparative analysis of COPD associated with tobacco smoking, biomass smoke exposure or both. Respir Res. 2018;19:1-8.

56. Torres-Duque CA, Caballero A, González-García M, Jaramillo C. Chronic obstructive pulmonary disease in people exposed to wood smoke. PREPOCOL: a population based study. Am J Respir Crit Care Med. 2013;187:A3644.

57. Ramírez-Venegas A, Sansores RH, Quintana-Carrillo RH, et al. $\mathrm{FEV}_{1}$ decline in patients with chronic obstructive pulmonary disease associated with biomass exposure. Am J Respir Crit Care Med. 2014;190:996-2

58. Golpe R, Mengual-Macenlle N, Sanjuan-López P, et al. Prognostic indices and mortality prediction in COPD caused by biomass smoke exposure. Lung. 2015;193:497-3.
59. Gelb AF, Zamel N, Hogg JC, Müller NL, Schein MJ. Pseudophysiologic emphysema resulting from severe small-airways disease. Am J Respir Crit Care Med. 1998;158:815-9.

60. González-García M, Torres C, Jaramillo C, Maldonado D, Bustos D. Bronchial hyperresponsiveness in women with chronic obstructive pulmonary disease related to wood smoke. Int J Chron Obstruct Pulmon Dis. 2012;7:367-73.

61. Guzmán-Bouilloud NE, Velázquez-Uncal M, Aranda-Chávez A, et al. Roll of small airways in patients with chronic obstructive pulmonary disease associated to biomass smoke. Am J Respir Crit Care Med. 2017:195:A5009.

62. Miravitlles M, Soler-Cataluña J], Calle M, et al. Guía española de la EPOC (GesEPOC). Actualización 2014. Arch Bronconeumol. 2014;50:1-16.

63. Sertogullarindan B, Gumrukcuoglu HA, Sezgi C, Akil MA. Frequency of pulmonary hypertension in patients with COPD due to biomass smoke and tobacco smoke. Int J Med Sci. 2012; 9:406-12

64. Sandoval J, Salas J, Martínez-Guerra ML, et al. Pulmonary arterial hypertension and cor pulmonale associated with chronic domestic woodsmoke inhalation. Chest. 1993;103:12-20.

65. Mehra D, Geraghty PM, Hardigan AA, Foronjy R. A Comparison of the inflammatory and proteolytic effects of dung biomass and cigarette smoke exposure in the lung. PLoS One. 2012 7:e52889. 